\title{
Evaluation on College Students' Usage of Micro-channel circle of friends in Interpersonal Communication
}

\author{
He Zichen ${ }^{1,}$, Yang Fan ${ }^{2, ~ b}$, Yang yan ${ }^{3, c}$, Ye sishi ${ }^{4, d}$ \\ ${ }^{1,2,3,4}$ College of communication, Chongqing Normal University, Chongqing 400000, China \\ A,b,c,d 632431317@qq.com
}

Keywords: Micro-channel circle of friends, interpersonal communication, evaluation model, related

\begin{abstract}
In order to analyse the influence of Micro-channel circle of friends on college students' interpersonal communication, based on the evaluation models constructed in the respects of self-awareness, self expression, and self-image building, this thesis designs entropy value method to empower. It is to evaluate in the way of determining index weight according to the size of the information provided by the observation, and it has effectively promoted the interpersonal communication among college students for the influence of Micro-channel circle of friends on college students' self-awareness, self-expression, and self-image building is positively related according to the data got from statistical analysis of correlation and regression analysis.
\end{abstract}

\section{Introduction}

In the information age, mobile network has accelerated the development of new media. Wechat marks the beginning of a new communication mode - instant communication. The majority of user group of Micro-channel circle of friends is college students, and Micro-channel circle of friends has become a new tool of college students' external liaison, and also represents a new way of college students' social commucation. Micro-channel circle of friends provides a social communication space with a diversity of information, enriches the means of communication, fulfill the content of communication, and increase the frequency of communication. The network community with the function of Micro-channel circle of friends now has become a typical representative of virtual community. As the most active group of this era, college students are also the main users of Micro-channel circle of friends. Interpersonal relationship is an important part of college students' learning and life, but is also one of the important problems during the grouth of college students, and the stand or fall of relationship influences college students' mental health. With students as the main body of Micro-channel circle of friends interpersonal communication circle, Micro-channel circle of friends has a big impact on the interpersonal communication of both real and network society.

Taking college students including graduate students and a few doctoral students as the target group, this thesis builds a virtual community to study the impact on college students' interpersonal communication through questionnaire survey. College students reasonably use Micro-channel circle of friends to construct harmonious relationships on which Micro-channel circle of friends exerts a great influence.

\section{Evaluation model of the interpersonal communication on Micro-channel circle of friends}

This study attempts to expose the influence of Micro-channel circle of friends on College Students' interpersonal relationship by using micro analysis of college students, and then summed up more objective understanding of the influence of Micro-channel circle of friends on college students' interpersonal relationships through the investigation of the impact of Micro-channel circle of friends on college students' self awareness, self expression, self image establishment.

Due to the self cognition, the individual can know himself comprehensively and objectively. The ability of self expression determines whether he is capable of establishing and developing interpersonal relationship, so as to help the individual form a good interpersonal relationship. At the 
same time, when the individual is expressing himself, he could reevaluate himself, which will promote his new self cognition and further the understanding of others. And a good self-image is the beginning of building interpersonal relationship. Through self awareness, one can adjust self image at any time, which will help college students leave a good impression on others at the beginning of interpersonal relationship establishment. By investigating the influence of Micro-channel circle of friends on interpersonal relations of college students, college students will have a more comprehensive and objective understanding of the influence which internet has on their daily work and life, which helps the individual better use Micro-channel circle of friends and other social networking tools to maintain, expand their interpersonal relationship, and increase their social ability as well as competitiveness. Specific evaluation model is as follows:

The evaluation model in the thesis has such indicators as "maximum" or "minimum". It is supposed that there are $n$ decision-making indicators like $\mathrm{f}_{\mathrm{j}}(1 \leqslant \mathrm{j} \leqslant \mathrm{n}), \quad$ m schemes like $\mathrm{a}_{\mathrm{i}}(1 \leqslant \mathrm{i} \leqslant$ $\mathrm{m}$ ), and decision-making matrix $\mathrm{X}=\left(\mathrm{x}_{\mathrm{ij}}\right)_{\mathrm{mxn}}$ formed by $\mathrm{n}$ indicators. Supposing:

$$
y_{i j}=\frac{x_{i j}-\overline{x_{j}}}{s_{j}},(1 \leq i \leq m, 1 \leq j \leq n)
$$

Sample value and standard deviation:

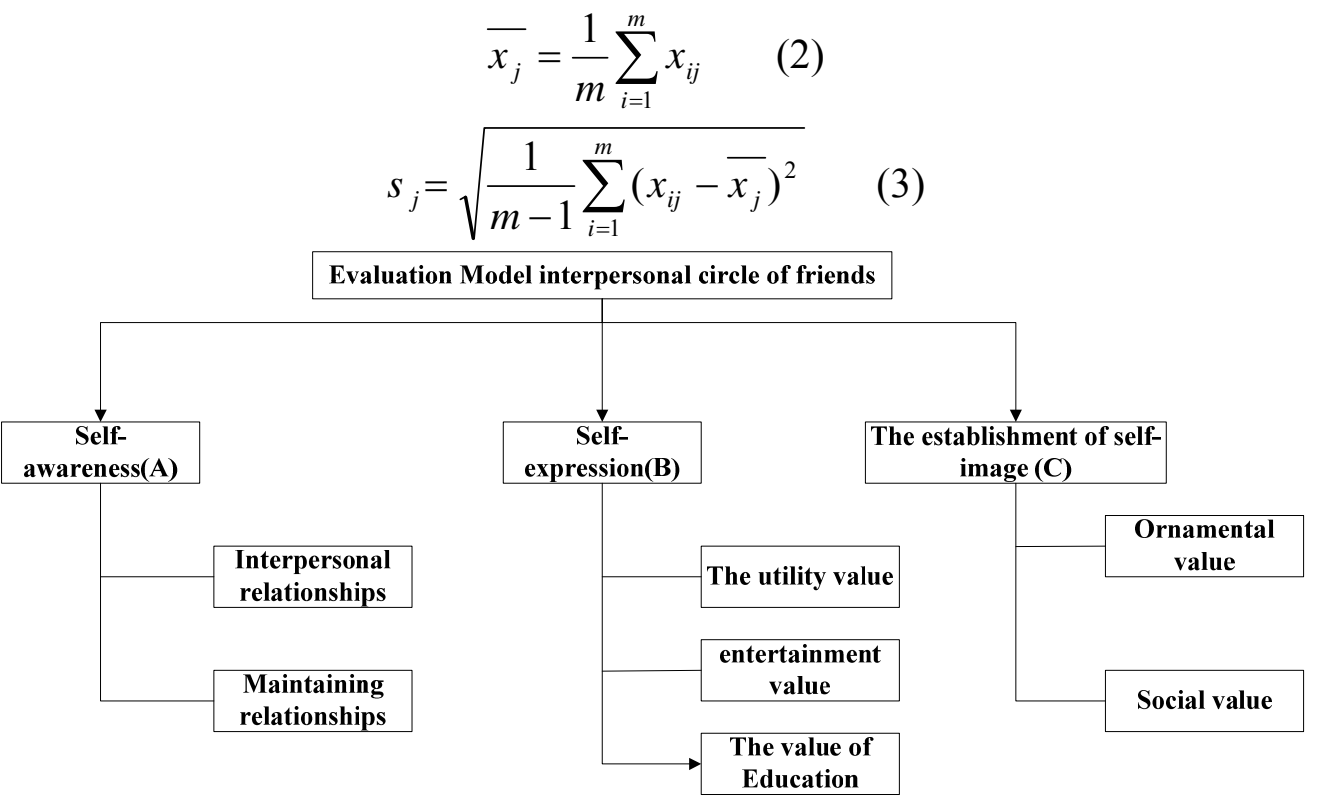

Figure 1 Evaluation model interpersonal circle of friends

Suppose that layer A and B have dominated relations, then to the above matrix, the weight of each element in the layer $\mathrm{B}$ like $\mathrm{B} 1, \mathrm{~B} 2, \ldots \mathrm{Bn}$ for the layer $\mathrm{A}$ is determined by the relative importance of every two elements on layer B after comparing. we assume that bij is the relative importance, that is to said that to $\mathrm{A}$, the relative importance of $\mathrm{Bi}$ to $\mathrm{Bj}$ or $\mathrm{Bj}$ to $\mathrm{Bi}$. This measure of the relative importance is called scale. When Saaty put forward analytic hierarchy process (ahp), he also gives a 1-9 scaling method, which can quantitatively describe the comparison of the two factors, as shown in table 1: 
Table 1 Meaning table of judging matrix scale by ahp

\begin{tabular}{cc}
\hline Scale value & Meaning \\
\hline 1 & $\mathrm{Bi}$ and $\mathrm{Bj}$ have the same importance \\
3 & $\mathrm{Bi}$ is a bit more important than $\mathrm{Bj}$ \\
5 & $\mathrm{Bi}$ is obviously more important than $\mathrm{Bj}$ \\
7 & $\mathrm{Bi}$ is much more important than $\mathrm{Bj}$ \\
9 & $\mathrm{Bi}$ is extremely more important than $\mathrm{Bj}$ \\
$2 、 4 、 6 、 8$ & $2,4,6,8$ indicates the mid-value of $1-3,3-5,5-7,7-9$ respectively \\
Reciprocal & judgement Bij got by comparing $\mathrm{Bi}$ and $\mathrm{Bj}$, \\
& while judgement $\mathrm{Bji}=1 / \mathrm{Bij}$ got by comparing $\mathrm{Bj}$ and $\mathrm{Bi}$ \\
\hline
\end{tabular}

The thesis uses entropy value to empower, which is a kind of method to determine index weight according to the amount of the information provided by the observed values. Let us suppose that there are $m$ evaluation objects (different time points, etc.), $n$ evaluation indexs, and the matrix of the original data is $X_{i j}=\left(x_{i j}\right)_{m \times n}$, among which the $x_{i j}$ indicates the numerical value of the jth indicator of the ith investigation object.

(1) $x_{i j}$ is standardized according to the linear proportion transformation method, then a standard matrix is formed;

(2) Compute indicators of the jth value entropy e and information utility value $d$.

$$
e=-k \sum_{i=1}^{m} y_{i j} \text { Iny }_{i j},(i=1,2, \mathrm{~K}, m ; j=1,2 \mathrm{~K}, n)
$$

Among them, $k=-(\mathrm{Inm})^{-1}$ is a constant related to the sample size of the system $\mathrm{m}$. For a completely disordered systems, the degree of order is 0 , its entropy is the largest, e $=1$; when $\mathrm{m}$ samples are in a state of complete disorder distribution $y_{i j}=1 / \mathrm{m}$

$$
e=-k \sum_{i=1}^{m} \frac{1}{m} \operatorname{In} \frac{1}{m}=k \sum_{i=1}^{m} \frac{1}{m} \operatorname{Inm}=k \operatorname{Inm}=1
$$

\section{Research data and method}

Questionnaire is collected mainly through the network questionnaire production software and most of the questionnaires are issued online. After two weeks of questionnaire distribution and collection, a total of 329 questionnaires were taken back, except for non-Micro-channel circle of friends users and invalid questionnaire, there are 312 effective questionnaire, and the effective rate is $94.83 \%$. Demographic statistics are as follows: gender: male, 143, 45.83\% : female, 169, 54.17\%. The recollected sample data is analysed by SPSS17.0 software in the study. Through descriptive statistical analysis the distribution of individual data is observed, and then the degree of consistency between each items is tested through the reliability analysis. Then the degree of effective of each item to variables is tested through the analysis of the validity, model hypothesisto is finally tested by correlation analysis and regression analysis. In this research, reliability is represented by Alpha coefficient which is the most commonly used. The criteria of reliability coefficient in this study is shown in table 2 .

table 2 The criteria of reliability coefficient

\begin{tabular}{llc}
\hline & Reliability coefficient of questionnaire & Reliability coefficient of univariate \\
\hline a & 0.7 & 0.5 \\
\hline
\end{tabular}

If the Alpha coefficient of the entire scale is above 0.7 , and that of each variable is above 0.5 , the reliability of the scale is good, and we can continue to analyse. 


\section{Result analysis of the evaluation}

As it is shown in table 3 , it is, after the evaluation of the model, the sequence of the effect of Micro-channel circle of friends on college students' self awareness, self expression, and self image setting. It can be seen that Micro-channel circle of friends can help college students form all-round objective self perception, improve their interpersonal skills, and extend relationships to a certain extent.

Table 3 The sequence of positive and negative ideal solution values of the indicators

\begin{tabular}{ccc}
\hline Indicators & Positive and negative ideal solution values & Sequence \\
\hline Self awareness & 0.17684563 & 1 \\
Self expression & 0.127167978 & 2 \\
Self image setting & 0.08405815 & 3 \\
\hline
\end{tabular}

The entire questionnaire and the two factors in it were analysed with estimation method of a reliability coefficient, and the results are shown in the table below. The a in self awareness $=0.922$, $\mathrm{a}$ in self expression $=0.889$, $\mathrm{a}$ in self image setting $=0.913$. The a coefficients of the subscales are above 0.8 , and that of the overall scale is 0.934 , which shows that the reliability test is very ideal.

Table 4 The analysis of factors

\begin{tabular}{ccc}
\hline Factors & Alpha coefficients & Information amount \\
\hline Self awareness & 0.922 & 8 \\
Self expression & 0.899 & 6 \\
Self image setting & 0.913 & 6 \\
Total amount of interpersonal & 0.934 & 20 \\
communication & & \\
\hline
\end{tabular}

In order to study the relationships between the behavior of using Micro-channel circle of friends and the time and frequency of using it, we studied the correlation. The values range of the correlation coefficient is between 1 and +1 , and the correlation coefficient is between 0 and 1 , that means the variables are correlated positively, while the correlation coefficient is between -1 and 0 , that means the variables are correlated negatively. Specific analysis of the results is as follows:

Table 5 The analysis of the scores of Micro-channel circle of friends using time and behavior

\begin{tabular}{cccc}
\hline & $\begin{array}{c}\text { Time of using } \\
\text { Micro-channel circle } \\
\text { of friends }\end{array}$ & $\begin{array}{c}\text { Information } \\
\text { acquiring }\end{array}$ & $\begin{array}{c}\text { Communication and } \\
\text { expression }\end{array}$ \\
\hline $\begin{array}{c}\text { Time of using Micro-channel } \\
\text { circle of friends }\end{array}$ & 1 & -.161 & $-.337^{*}$ \\
$\begin{array}{c}\text { Information acquiring } \\
\text { Communication and expression }\end{array}$ & -.161 & 1 & .000 \\
\end{tabular}

*. It is related obviously at the same level (two sides).

Table 4 shows that the scores of the time of Micro-channel circle of friends using and that of information acquring are correlated negatively, but it is not so obvious $(\mathrm{P}>0.05)$; and that of the time of Micro-channel circle of friends using and that of communication and expression are correlated negatively, which is obvious. $(/=0.337, \mathrm{P}<0.05)$.

Table 4 shows that the scores of the frequency of Micro-channel circle of friends using and that of information acquring are correlated positively, but it is not so obvious $(\mathrm{P}>0.05)$; and that of the frequecncy of Micro-channel circle of friends using and that of communication and expression are correlated positively, which is obvious. $(/=0.550, \mathrm{P}<0.05)$. 
Table 6 The analysis of the scores of Micro-channel circle of friends using frequency and behavior

\begin{tabular}{|c|c|c|c|}
\hline & $\begin{array}{l}\text { Information } \\
\text { acquiring }\end{array}$ & $\begin{array}{l}\text { Communication and } \\
\text { expression }\end{array}$ & $\begin{array}{c}\text { Time of using } \\
\text { Micro-channel circle } \\
\text { of friends }\end{array}$ \\
\hline Information acquiring & 1 & .000 & -.132 \\
\hline Communication and expression & .000 & 1 & $-.550 * *$ \\
\hline $\begin{array}{l}\text { Time of using Micro-channel } \\
\text { circle of friends }\end{array}$ & $.132 *$ & $-.550 * *$ & 1 \\
\hline
\end{tabular}

\section{Evaluation conclusion and suggestion}

(1) College students building interpersonal relationships by Micro-channel circle of friends

Form of self image setting: self-image is external image of each social individual, and it gets others' attention and evaluation in the flat space of the Internet. These attention and evaluation are feedbacks from software users to the clients in the forms of short messages through internet instead of face to face. In the flat space of the Internet, the establishment of the relationship between different individuals is random, Micro-channel circle of friends users get to know different people, so there is uncertainty in network communication, and individuals are usually playing several different roles. In the same way, strangers in the real world can also build relationships through Micro-channel circle of friends. Micro-channel circle of friends provides individuals a lifelike social platform that has extremely rich content.

(2) The effects of Micro-channel circle of friends on college students' interpersonal relationship

When college students are using Micro-channel circle of friends, they can get a lot of real-time news through the information released by friends circle, public accounts, and Micro-channel circle of friends platform, which can help college students communicate with each other, contact the society, and complete the process of participation in society. The use of Micro-channel circle of friends by college students can increase the degree of individual information exchange, and help them get a lot of real-time news and consulting, communicate information with others, contact the society, and complete the process of participation in society. College students can use Micro-channel circle of friends to consolidate its existing relationships, which can deepen the degree of people's interpersonal communication, diversify and enrich the expressment, deepen the understanding between individuals, close the relationship between people, strengthen interpersonal relationships, at the same time, increase the credibility between people. Micro-channel circle of friends can help students form objective and complete self awareness, and the deeper the level of college students using Micro-channel circle of friends, the more objective self awareness is; the longer the time fo College students using Micro-channel circle of friends, the more it will help form their self images; the deeper the level of college students using Micro-channel circle of friends, the more it will help form their self images.

(3) The mode of Micro-channel circle of friends improving interpersonal communication

Micro-channel circle of friends can barely help college students establish new relationships, but it can help them improve existing relationships. Because college students need to learn, so they live in a fixed area for a long time, they lack an effective way to sustain relationships. They can use Micro-channel circle of friends to improve interpersonal relationships, and learn interpersonal skills from the traditional culture. School should strengthen the education of network security and improve college students' consciousness of self discipline, strengthen the social networking management, actively implement the real-name system of social networking and other social rules, and improve moral ethics and norms of social networking. To some extent, there is positive correlation relationship, but it has certain negative impact on the establishment of healthy and positive relationships. The appearance of Micro-channel circle of friends has resulted in the silent state of relationships in real life, so the application of Micro-channel circle of friends will not exert too much positive influence on college students' interpersonal relationship in real life. 


\section{References}

[1]] Wang Yao. Micro-channel circle of friends and Micro Communication. New Media Research. 2013, PP. 135-165.

[2] Wang Huan, Zhu Yang. Research on the Function of Micro-channel circle of friends from Interpersonal Perspective. Modern Intelligence, vol 34 (2), 2014, PP. 82-85.

[3] Zhao Yang. Analysis of the Impact of "Micro-channel circle of friends" Application on Social Networking. Innovation BBS, Vol 4201, pp15-17.

[4] Hu Rong, Deng Xiaozhao. Research on Trust Issues in the Interpersonal Interaction on the Internet. Knowledge of Books Intelligence, Vol 8200, pp. 98-101.

[5] Wang Zhaorui. Research on Trust Issues of College Students' Interpersonal Communication Under the New Media Environment. Gansu, Lanzhou University, 2013.

[6] Chu Jinglun. The Present Situation and Coping Strategies of Micro-channel circle of friends Media. New Media Focus, 2014 (9), pp. 71-73.

[7] Yang Xunbing. Research on Weibo Application in Ideological and Political Education in Higher Vocational Colleges. Journal of Hubei Correspondence University, 2011 (8) : 52-53

[8] Lu Guitao, Research on the Impacts of Internet on College Students' Interpersonal Communication---with Hunan City University as an Example. Journal of Hunan City University, 2010, pp13-15.

[9] Cai Maozhou, Chou Yi. New Medias Like Weibo and Their Development Trend. Heilongjiang Province Ecological Engineering Vocational College, 2013 (7), pp102-103 